\title{
Effects of Net Height Scale on Badminton Performance and Satisfaction among Children
}

\author{
Henry Kota Pirak ${ }^{1}$, Mohamad Nizam Nazarudin ${ }^{1, *}$, Mohd Firdaus Abdullah ${ }^{2}$ \\ ${ }^{1}$ Faculty of Psychology and Education, Universiti Malaysia Sabah, 88400 Kota Kinabalu, Sabah, Malaysia \\ ${ }^{2}$ Institute of Technology Management and Entrepreneurship, Universiti Teknikal Malaysia Melaka, 76100 Melaka, Malaysia
}

Received July 11, 2021; Revised August 23, 2021; Accepted September 21, 2021

\begin{abstract}
Cite This Paper in the following Citation Styles
(a): [1] Henry Kota Pirak, Mohamad Nizam Nazarudin, Mohd Firdaus Abdullah, "Effects of Net Height Scale on Badminton Performance and Satisfaction among Children," International Journal of Human Movement and Sports Sciences, Vol. 9, No. 6, pp. 1272 - 1283, 2021. DOI: 10.13189/saj.2021.090622.
\end{abstract}

(b): Henry Kota Pirak, Mohamad Nizam Nazarudin, Mohd Firdaus Abdullah (2021). Effects of Net Height Scale on Badminton Performance and Satisfaction among Children. International Journal of Human Movement and Sports Sciences, 9(6), 1272 - 1283. DOI: 10.13189/saj.2021.090622.

Copyright $\bigcirc 2021$ by authors, all rights reserved. Authors agree that this article remains permanently open access under the terms of the Creative Commons Attribution License 4.0 International License

\begin{abstract}
The height of the net scaling accordance with the physical size is important to improve performance and produce optimal shot kinematic characteristics in children. This study aimed to identify the average rate of optimal net height scaling among children aged seven to nine years. This study uses an experimental design with a total of 48 children randomly selected as study participants. Participants were divided into 24 pairs (boys $=12$ pairs, female $=12$ pairs) which were equivalent in terms of skill level and gender. All participants played against their respective pairs using four net height situations namely JP $(155 \mathrm{~cm})$ JM100 $(127 \mathrm{~cm})$ JM92 $(117 \mathrm{~cm})$ and JM82 (104 $\mathrm{cm})$ situations reciprocally. All matches are conducted using a singles competition system with 11 points which is two sets per match situation. Data collection was done through video recordings and questionnaires. Shot performance was analysed from the aspects of serve success, shot chances and rally length. Participants' satisfaction with the four paired match situations was obtained through a questionnaire. Study data were analysed using SPSS version 16.0 program. The results of one-way ANOVA test for repeated measurements showed that there was significant mean score differences $(\mathrm{p}<.05)$ for performance and satisfaction between the JP, JM100, JM92 and JM82 situations. The findings of the study showed that scaling the net height of $92 \%$ of the average height of children aged seven to nine years was the optimal net height. Therefore, this study suggests that the use of standard net heights among children should be reviewed.
\end{abstract}

Keywords Scaling, Net Height, Performance, Badminton, Satisfaction, Children

\section{Introduction}

Mastery of motor skills as early as childhood is important efforts to form the foundation of a healthy living culture and continued involvement in sports [1]. This goal can be achieved through the provision of a conducive motor skills mastery environment [2,3]. A conducive environment is necessary to provide high opportunities and experiences of success among children. Increased experience of success can be achieved through a reduction in the complexity of a task learned. Involvement in sports should be consistent with the age and developmental stage of the child [4]. Low physical ability will lead to problems of less enjoyable activities, boredom and frustration. In turn, these problems lead to withdrawal from continued involvement in sports. A study reported that $38 \%$ of girls and $39 \%$ of boys had withdrawn from continuous involvement in sports as a result of less enjoyable activities [5]. One of the main factors of children and adolescents withdrawing from sports is due to less fun and boring activities [6].

The selection of high-impact approaches that can improve the mastery of motor skills and performance among children is one of the main challenges that need to 
be faced by sports activists. Therefore, there is a need to apply an instructional approach based on an effective theoretical framework. For a long time, the field of motor skill mastery has applied a variety of conventional approaches in the form of technical, prescriptive and repititive demonstrations [7]. This conventional approach adheres to the notion that every motor skill has an ideal movement pattern as a model to be learned. The role of the coach according to this approach is to reshape the movement pattern of the skill according to the ideological model that he holds. One of the model capable of improving the mastery of motor skills in children is the Constraints-Led Approach [8]. Constraints are defined as obstacles or limitations faced by the performer during the process of mastery of motor skills [8]. Past studies related to the Constraints-Led Approach have emphasized the constraint manipulation approach especially task constraints as an effective method in the process of mastering motor skills $[9,10,11,12]$.

Referring to this approach, the results of effective modifications to task or environmental constraints are able to influence the intention of actors to explore functional movement patterns and decision -making behaviors that aid problem solving in real environments [10]. This means, the result of effective task constraint modification is able to increase the chances of mastery of motor skills through an ecologically enabling environment and in turn increase the diversity as well as creativity of movement [12]. According to this approach, the performer will personally make adjustments or modifications to his motor behavior when faced with constraints. Newell categorizes these constraints into task, environmental and individual constraints. All three of these constraints can be manipulated to improve mastery of motor skills and performance in children. Task constraints can be manipulated through an equipment scaling approach by reducing the complexity of tasks performed appropriate to the child's physical size $[10,13,14]$. Therefore, there is a need to apply an effective approach to improve the mastery of motor skills and performance among children. One of the approaches that can have an impact towards the achievement of these goals is through equipment scaling.

\section{Research Background}

Previous studies have shown that the net height scaling approach among children is able to improve mastery of motor skills and performance particularly in tennis and badminton games [15, 16, 17] Nevertheless, to this day, the game of badminton still uses standard net heights for all ages whether for training or competition purposes. The standard net height was determined based on $92 \%$ of the average adult height $(165 \mathrm{~cm})$. Moreover, there are no clear scaling guidelines for determining the appropriate net height in children. Nevertheless, there have been several efforts among researchers to explore this problem [15]. The study used a scaling rate of $92 \%$ of the average height of study participants aged nine to eleven years to determine the height of the nets used.

Meanwhile, the net height variable is a side variable in this study. These studies report the positive impact of the equipment scaling approach on motor skill mastery and game performance. Nevertheless, there is ambiguity in terms of the guidelines used to determine the appropriate average rate of scaling according to the age and skill level of the children. In addition, there is ambiguity in terms of the average optimal net height among children. This average height is important to determine the transition period to the use of standard equipment in the future.

In turn, this situation is able to influence the performance of children's play especially in terms of service success, shot chances and rally length. In addition, the large projection angle also causes children to have to do shots with high force. This action aims to get the projection speed needed to ensure that the badminton hit is past the net and hitting the desired target. This task becomes more difficult when children are forced to play using standard rackets and standard courts. Based on these constraints, there is a need to identify the optimal net height and appropriate for the child's developmental stage. One of the purposes of children's involvement in sports activities is for fun. The fun of playing in the game of badminton is influenced by the number of shots successfully performed or the length of the rally. The use of standard net heights among children causes them to have to use high force while making shots towards the desired target. It aims to ensure that each shot is done successfully and hits the target. This situation can affect the number of shots successfully made and the length of the rally of a game.

Studies have also shown that too low a net height has led to a decrease in terms of shot chances. This decreased chance of a shot occurs due to a rally being terminated quickly as a result of the high projection speed. In addition, the effect of the use of standard net heights or incompatibility with children's height is able to affect the enjoyment of play among children. This situation will affect the self-efficacy and motivation of children to continue to be involved in this sport in the future. Based on these problems, there is a need to obtain further empirical evidence on the optimal rate of net height scaling appropriate to the child's level of physical development and skill using real match situations. This is because many past studies have focused on the effects of equipment scaling from the perspective of motor skill mastery conducted during the intervention program and not based on actual match situations. Thus, this study aimed to identify the effect of net height scaling on play performance and satisfaction among children aged seven to nine years. In addition, this study also aimed to 
determine the optimal net height among children aged seven to nine years.

This study was conducted to achieve the following objectives:

1. Identify the differences in service success performance of the effect of net height scaling between situations JM82, JM92, JM100 and JP.

2. Identify the difference in shot chance performance of the effect of net height scaling between situations JM82, JM92, JM100 and JP.

3. Identify the difference in rally length performance of net height scaling effect between JM82, JM92, JM100 and JP situations.

4. Identify the difference in satisfaction of net height scaling effect between situations JM82, JM92, JM100 and JP.

\section{Methodology}

\section{Research Design}

This study is in the form of quantitative research and uses an experimental research design. This design was chosen because it allows the researcher to see the effect of the independent variable on the dependent variable. In addition, this design also allows data to be collected from a single sample in several different times and situations in the study. The independent variable that has been manipulated in this study is the measurement of net height which is divided into four situations namely JP, JM100, JM92 and JM82 situations. Whereas, the dependent variables consisted of shot performance and satisfaction.

\section{Participants}

The sample selection in this study was conducted randomly. Study participants consisted of a total of 48 children, namely boys $(\mathrm{n}=24)$ and girls $(\mathrm{n}=24)$ aged seven to nine years (boys: $\mathrm{M}=8.46, \mathrm{SD}=.779$; girls: $\mathrm{M}=$ $8.29, \mathrm{SD}=.751)$. The selection of participants was done on the basis that this group of children was the most affected as a result of the use of standard net heights. The average height of the participants was $(\mathrm{M}=1.27, \mathrm{SD}=$ 4.66) and the average weight of the participants was $(M=$ 28.83, SD = 3.01). Participants of this study were randomly selected from four primary schools in Marudi, Sarawak. According to this sampling method, each boy and girl's student aged seven to nine years from these four schools is given a number. Next, the selection was done using GraphPad Software. This random selection aims to ensure that possible biases in individual characteristics are evenly distributed among study participants. Study participants were comprised of novice players who had no formal experience in the game of badminton. This means that the participants' involvement in the game of badminton is in the form of recreation only.

To ensure that the study population was equivalent, children were excluded from the study if (i) they had attended a badminton coaching program for more than one school term before the study was conducted, (ii) were attending a badminton coaching program while the study was being conducted, or (iii) had represented a school or any sports organization in the period before this study was conducted. This unequal population is capable of posing a threat of unusual score propensity or large performance score difference gaps during the course of the study. The number of participants involved in this study was determined using power analysis method. This power analysis aimed to determine the number of participants was sufficient to produce a high validity of the study. This analysis was conducted based on the effects of size, alpha value, number of repetitions and number of groups. For this study, the effect size was $\mathrm{f}$ value $=.85$, alpha value $=$ 0.05 , number of repetitions $=4$ and 24 pairs. The power analysis report showed that the total of 48 participants was in excess of the requirement to produce study findings that had a high validity of $85 \%$.

\section{Data Collection Procedure}

The procedure of this study is divided into two parts namely general procedure and specific procedure. General procedures discuss the general study procedures that need to be followed in conducting this study. Meanwhile, the specific procedure consists of rally test procedure, paired match procedure and video recording procedure. The data collection process for the paired match phase was done through video recording. The brand of video camera used is Canon Legria HF M56. This video camera is capable of recording 60 frames per second. The frame rate of the video camera has been set at 60 frames per second. Meanwhile, the shutter speed is $1 / 120$. The video recording process was performed using a video camera placed perpendicularly parallel to the net. The distance of this video camera from the centre of the line of the badminton court is eight meters.

This procedure was adapted from the study of [18] who studied the trajectory of badminton while performing short serves. To ensure clear recording quality and cover the width and height of the badminton, a video camera was mounted on a tripod with a fixed position at a height of 1.21 meters from the surface of the court. This video camera height measurement procedure was adapted from the study in badminton. $[19,20]$ After the video recording of the pairing match had ended, all the data was downloaded into the computer for analysis purposes. The study was conducted for three weeks which was divided into two phases namely the participant classification phase and the paired match phase. The participant classification phase was conducted in the first week. Meanwhile, the paired match phase was conducted in the second and third weeks. 
The participant classification phase was conducted for one week. This phase aims to categorize participants according to position before running the paired match phase. Based on this position, participants were divided into equal pairs based on skill level and gender. The division of participants into equal pairs was done based on the results of the rally test. This instrument was adapted from the study of Farrow and Reid [13]. Rally test performance was determined based on the number of successful rally shots performed from 10 rally attempts. In total, each participant was given 10 rally trials. For the purpose of rally test performance analysis, data collection process was performed using video recording.

The paired match phase was conducted for two weeks, in the second week and the third week. During the course of this phase, participants were randomly divided into 24 equivalent pairs. All participants played against each other using four net height situations, namely standard net situation (JP), 100\% modified net situation (JM100), 92\% modified net situation (JM92) and $82 \%$ modified net situation (JM82). Specifically, the height of the net is situation JP (155 centimetre's), situation JM100 (127 centimetres), situation JM92 (117 centimetres) and situation JM82 (104 centimetre's). The situational net heights of JM100, JM92 and JM82 were determined based on the scaling concepts of $100 \%, 92 \%$ and $82 \%$ of the average heights of the study participants. All participants played against their respective pairs using the badminton singles competition system with a score of 11 points. Each study situation consisted of two sets of games (two sets $\mathrm{x}$ four situations $=$ eight sets). The sequence between each study situation was conducted reciprocally. Paired match data for each pair of participants in all four net height situations were collected and recorded in terms of shot performance and satisfaction. Performance variables were analysed from the aspects of serve success, shot chances and rally length.

\section{Research Equipment}

The data collection process for all stages of the study was performed using a standard racket. The racquet used is Fleet Power 10 brand. The frame of the racquet is made of graphite material. The weight of the racket is categorized as moderate, which is 84 grams to 86 grams. Meanwhile, the length of the racket is 66.5 centimetres. The racket rope tension used is categorized as a moderate tension level of 18 pounds. Generally, novice players use a low rope tension of between 18 pounds to 25 pounds. The tension of this rope was chosen because it was appropriate for the age level and physical size of the study participants. The badminton used for the purpose of this study is standard size which is the brand RSL Tourney No.1 Classic Series (77). Badminton is made from natural goose feathers. This badminton has 16 feather fronds with a skirt diameter of 65 millimetres. Meanwhile, it weighs 5.0 grams and its length is 85 millimetres. The speed of badminton is categorized as slow to moderate which is between 73 to 81 . Specifically, this badminton is suitable for use in countries with a temperature of 27 to 38 degrees Celsius and is at sea level such as Malaysia. The selection of badminton was done based on the factors of high endurance, flight stability, trajectory and speed level appropriate to the study location. In addition, this badminton brand is also suitable for use in competitions or matches.

This study uses a standard size badminton court measuring 6.1 meters x 13.40 meters. For the purpose of this study, the size of the singles event court was used which measured 5.18 meters $\times 13.40$ meters. These ring measurements were used to collect data for all stages of the study. This type of ring surface layer is made of concrete. The court floor is green with white lines. This study uses four net height situations, namely JP situation, JM100 situation, JM92 situation and JM82 situation. Paired matches in JP situations use a standard net height of 155 centimetres. Meanwhile, the paired matches in the JM100, JM92 and JM82 situations used a modified net height. The height of the modified net for these three situations was determined based on the concept of scaling the average height of the study participants which is $100 \%$ (situation JM100 - 127 centimetres), 92\% (situation JM92- 117 centimetres) and 82\% (situation JM82 - 104 centimetres).

The average height of the study participants was 127 centimetres. This assumption is based on the guidelines that have been used to determine the standard net height by the World Badminton Federation which is based on $92 \%$ of the average height of adults (Jackson, 2012). The average height of an adult is 165 centimetres (Department of Health and Human Services, Centres for Disease Control and Prevention, 2002). This questionnaire was adapted from the study of Abdul Muiz et al. [21]. This questionnaire contained four questions on participants satisfaction with the four net height situations. After finishing the match in each study situation, all participants were asked to fill out this questionnaire. Participants were required to select one of the four responses based on their perceptions of each net height situation. Among the four responses were (i) most of the time I felt bored, (ii) most of the time I didn't feel bored but I was really not interested in what I was doing, (iii) most of the time I was quite interested in what I was doing, and ( vi) most of the time I like what I do.

\section{Data Analysis}

The data were analysed using SPSS version 16.0. The effects of net height scaling on projection height, projection angle and projection speed were reported in the form of descriptive and inferential statistical analysis. Meanwhile, inferential statistical analysis used one-way ANOVA test for repeated measurements to compare the differences between the four net height situations namely 
JP, JM100, JM92 and JM82 situations.

\section{Results}

The reliability test analysis of the questionnaire showed that for this study instrument, Cronbach's Alpha reliability coefficient was .89 and game performance which included serve success, shot chance and rally length consisting of 12 items showed Cronbach's Alpha reliability coefficient was .95 .

Table 1. Cronbach's Alpha Analysis

\begin{tabular}{lccc}
\hline & $\begin{array}{c}\text { Cronbach's } \\
\text { Alpha }\end{array}$ & $\begin{array}{c}\text { Cronbach's Alpha Based } \\
\text { on Standardized Items }\end{array}$ & Item \\
\hline Questionnaire & .89 & .896 & 4 \\
Performance & .952 & .963 & 12 \\
\hline
\end{tabular}

The normality test results for serve success, shot chance and rally length indicate that the data are normally distributed. Data analysis using the Shapiro-Wilk test was insignificant ( $p>.05$ ) for all four net height situations. Skewness and kurtosis tests show that the data are normally distributed where values in the range $+/-2$ are still considered normally distributed [22].

\section{Differences in Service Success Performance Effected by Net Height Scaling}

The test results showed that for the pair of participants of this study $(n=24)$, the mean score of service success performance for situation JM82 (situation JM82: M = $29.79, \mathrm{SD}=3.19$ ) was higher compared to situation JM92 (situation JM92: $\mathrm{M}=28.58, \mathrm{SD}=3.30$ ), situation JM100 (situation JM100: $\mathrm{M}=28.33, \mathrm{SD}=2.82$ ) and situation JP (situation JP: $\mathrm{M}=27.70, \mathrm{SD}=2.84$ ). These results indicate that the net height scaling approach based on $82 \%$ and $92 \%$ of the average height of children aged seven to nine years was more effective in improving service success performance in this study. On the other hand, the results of the study showed the lowest service success performance for the standard net height situation.

$H_{1}$ : $\quad$ There is a significant difference in the performance of service success of the net height scaling effect between situations JM82, JM92, JM100 and JP.

The result of Mauchly's Test of Sphericity for the effect of net height scaling on service success performance is significant $X^{2}(5)=16.71, p=.005$. The significant result of this test was non -compliance with the one -way ANOVA test requirement for repeated measurements. These results indicate that df (degree of freedom) adjustment for one -way ANOVA tests should be performed. Based on the new degree of freedom after adjustment using the Bonferroni method, at the significance level of $\mathrm{p}<.05$, the results of the Tests of Within-Subjects Effects show that there is a significant mean score difference for service success performance $[\mathrm{F}$ $\left.(2.12,48.7)=4.73, \mathrm{p}=.012, \eta \square^{2}=.170\right]$ between situations JP, JM100, JM92 and JM82. These results indicate that there are significant differences in terms of service success performance between JP, JM100, JM92 and JM82 situations.

Next, to determine which pair of net height situations had contributed to significant results for service success performance, the results in the Within-Subjects Contrasts were referenced. The results of the comparison test in the subjects showed that there was a significant difference from the aspect of service success between the JM92-JM82 situations $[\mathrm{F}(1,23)=8.58, \mathrm{p}=.008]$. The results of this comparative test indicate that this situation pair is a significant contributor to the test results for service success performance in this study. Meanwhile, test results also shown by the Pairwise Comparisons that compares the performance of serve success between the four net height situations. Paired comparison results showed a significant difference ( $p$ <.05) after Type I error was controlled using the Bonferroni method for the JP-JM82 situation $(\mathrm{p}=.005)$ and the JM92-JM82 situation $(\mathrm{p}=.045)$.

Table 2. Pairwise Comparisons for Serves Success

\begin{tabular}{cccc}
\hline $\begin{array}{c}\text { (I) } \\
\text { Serves } \\
\text { Success }\end{array}$ & $\begin{array}{c}(\mathbf{J}) \\
\text { Serves } \\
\text { Success }\end{array}$ & $\begin{array}{c}\text { Min } \\
\text { Difference } \\
(\mathbf{I}-\mathbf{J})\end{array}$ & Sig. \\
\hline \multirow{3}{*}{ JP Situation } & JM100 & -.625 & .832 \\
& JM92 & -.875 & 1.00 \\
& JM82 & $-2.08^{*}$ & .005 \\
JM100 & JP & .625 & .832 \\
Situation & JM92 & -.250 & 1.00 \\
& JM82 & -1.46 & .124 \\
JM92 & JP & .875 & 1.00 \\
Situation & JM100 & .250 & 1.00 \\
& JM82 & $-1.21^{*}$ & .045 \\
& JP & $2.08^{*}$ & .005 \\
JM82 & JM100 & 1.46 & .124 \\
Situation & JM92 & $1.21^{*}$ & .045 \\
\hline
\end{tabular}

*The value of the difference is significant at the level of 0.05 .

\section{Differences in Shot Chance Performance Effected by Net Height Scaling}

This study aimed to identify the effect of net height scaling on shot chance performance among children aged seven to nine years. To answer the questions of this study, one -way ANOVA test for repeated measurements was conducted to see the effect of net height scaling on shot chance performance between JP, JM100, JM92 and JM82 
situations. The test results showed that for the pair of participants in this study $(n=24)$, the mean score from the aspect of shot chance performance for situation JM92 (situation JM92: $\mathrm{M}=78.21, \mathrm{SD}=17.50$ ) was higher compared to situation JM100 (situation JM100: $\mathrm{M}=76.79$, $\mathrm{SD}=17.16$ ), situation JM82 (situation JM82: $\mathrm{M}=71.38$, $\mathrm{SD}=14.98$ ) and situation JP (situation JP: $\mathrm{M}=70.71$, SD $=15.43$ ). These results indicate that participants exhibited higher shot chance performance when playing using the JM92 situation compared to JP, JM100 and JM82. The findings of the study also show that the standard net height situation is less effective in improving the shot chance performance among the participants of this study.

\section{$\mathrm{H}_{2}$ : There is a significant difference in shot chance performance of net height scaling effect between situations JM82, JM92, JM100 and JP.}

This study aimed to see whether there was a significant mean score difference for shot chance performance between JP, JM100, JM92 and JM82 situations. The results of Mauchly's Test of Sphericity for the effect of net height scaling on shot chance performance were significant $\mathrm{X}^{2}(5)=16.7, \mathrm{p}=.014$. These results indicate that the adjustment of the degree of freedom for the one -way ANOVA test needs to be done because it does not comply with the conditions of the one -way ANOVA test for repeated measurements. The results of Mauchly's Test of Sphericity for the shot chance performance between the JP, JM100, JM92 and JM82 situations. Based on the new degree of freedom after adjustment using the Bonferroni method, at the significance level of $\mathrm{p}<.05$, the results of Tests of Within-Subjects Effects showed that there was a significant difference in mean score from the aspect of shot chance performance $[\mathrm{F}(2.31,53.2)=14.3, \mathrm{p}=.001$, $\left.\eta \square^{2}=.170\right]$ between situations JP, JM100, JM92 and JM82. Thus, hypothesis $\mathrm{H}_{2}$ is accepted. These results indicate that there are differences in terms of shot chance performance between the four net height situations in this study.

Next, to determine which pairs of situations contributed to significant shot chance performance results, the results of Within-Subjects Contrasts were referenced. The results of the comparison test in the subjects showed that there was a significant difference in the aspect of shot chance performance between situation JP-JM100 [F $(1,23)=$ $26.5, \mathrm{p}=.001]$ and situation JM92-JM82 [F $(1,23)=18.0$, $\mathrm{p}=.001]$. Whereas, the results of the comparison test in the subjects between situations JM100-JM92 [F $(1,23)=$ $1.12, \mathrm{p}=.301]$ were not significant. These results indicate that the pair of JP-JM100 situations and JM92-JM82 situations is a significant contributor to the test results for shot chance performance between JP, JM100, JM92 and JM82 situations in this study.

The results of Pairwise Comparisons for the shot chance performance between the JP, JM100, JM92 and JM82 situations are shown in Table 3 below.
Table 3. Pairwise Comparisons for Shot Chances

\begin{tabular}{|c|c|c|c|}
\hline $\begin{array}{c}\text { (I) } \\
\text { Shot Chances }\end{array}$ & $\begin{array}{c}(\mathrm{J}) \\
\text { Shot Chances }\end{array}$ & $\begin{array}{c}\text { Min Difference } \\
(\mathrm{I}-\mathrm{J})\end{array}$ & Sig. \\
\hline \multirow{3}{*}{ JP Situation } & JM100 & $-6.08^{*}$ & .000 \\
\hline & JM92 & $-7.50 *$ & .004 \\
\hline & JM82 & -.667 & 1.00 \\
\hline \multirow{3}{*}{ JM100 Situation } & JP & $6.08^{*}$ & .000 \\
\hline & JM92 & -1.42 & 1.00 \\
\hline & JM82 & $5.42 *$ & .000 \\
\hline \multirow{3}{*}{ JM92 Situation } & JP & $7.50 *$ & .004 \\
\hline & JM100 & 1.42 & 1.00 \\
\hline & JM82 & $6.83^{*}$ & .002 \\
\hline \multirow{3}{*}{ JM82 Situation } & JP & .667 & 1.00 \\
\hline & JM100 & $-5.42 *$ & .000 \\
\hline & JM92 & $-6.83^{*}$ & .002 \\
\hline
\end{tabular}

Paired comparison results showed significant difference ( $\mathrm{p}<.05)$ after Type I error was controlled using Bonferroni method for JP-JM100 situation $(\mathrm{p}=.001)$, JP-JM92 situation (.004), JM100-JM82 situation ( $\mathrm{p}=.001)$ and situation JM92 - JM82 ( $\mathrm{p}=.002)$. Meanwhile, the results of the paired comparison showed no significant difference $(p>.05)$ for the JP-JM82 situation $(p=1.00)$ and the JM100-JM92 situation ( $\mathrm{p}=1.00)$.

\section{Differences in Rally Length Performance Effected by Net Height Scaling}

This study aimed to identify the effect of net height scaling on rally length performance among children aged seven to nine years. To answer the questions of this study, one -way ANOVA test for repeated measurements was conducted to see the effect of net height scaling on rally length performance between JP, JM100, JM92 and JM82 situations. The test results showed that for the pair of participants of this study $(n=24)$, the mean score from the aspect of rally length performance for situation JM92 (situation JM92: $\mathrm{M}=59.46, \mathrm{SD}=14.63$ ) was higher compared to situation JM100 (situation JM100: $\mathrm{M}=56.79$, $\mathrm{SD}=13.03$ ), situation JM82 (situation JM82: $\mathrm{M}=52.46$, $\mathrm{SD}=11.92$ ) and situation JP situation (JP: $\mathrm{M}=51.33, \mathrm{SD}$ $=13.52$ ). These results indicate that participants exhibited higher rally length performance when playing using the JM92 situation compared to JM100, JM82 and JP. The findings of the study also show that the JP situation and the JM82 situation are less effective in improving the rally length performance among the study participants.

\section{$\mathrm{H}_{3} \quad$ There was a significant difference in rally length performance of net height scaling effect between situations JM82, JM92, JM100 and JP.}

This study aims to see whether there is a significant 
mean score difference for rally length performance between JP, JM100, JM92 and JM82 situations. The results of Mauchly's Test of Sphericity for the effect of net height scaling on rally length performance were significant $X^{2}(5)=16.70, p=.017$. These results indicate that the adjustment of the degree of freedom for the one -way ANOVA test needs to be done because it does not comply with the conditions of the one -way ANOVA test for repeated measurements. Based on the new degree of freedom after adjustment using Bonferroni method, at the significance level of $\mathrm{p}<.05$, the results of Tests of Within-Subjects Effects showed that there was a significant difference in mean score of rally length performance $\left[F(2.30,52.88)=30.37, p=.001, \eta \square^{2}\right.$ $=.170 \mathrm{~J}$ between situations JP, JM100, JM92 and JM82. Thus, hypothesis $\mathrm{H}_{3}$ is accepted. These results indicate that there are significant differences in rally length performance between the four net height situations in this study.

Table 4. Pairwise Comparisons for Rally Length

\begin{tabular}{cccc}
\hline $\begin{array}{c}\text { (I) } \\
\text { Rally Length }\end{array}$ & $\begin{array}{c}(\mathrm{J}) \\
\text { Rally Length }\end{array}$ & $\begin{array}{c}\text { Min Difference } \\
(\mathrm{I}-\mathrm{J})\end{array}$ & $\begin{array}{c}\text { Sig. } \\
\text { JP Situation }\end{array}$ \\
JM100 & -5.46 & .000 \\
& JM92 & -8.13 & .000 \\
& JM82 & -1.13 & 1.00 \\
\hline \multirow{3}{*}{ JM100 Situation } & JP & 5.46 & .000 \\
& JM92 & -2.67 & .027 \\
& JM82 & 4.33 & .000 \\
\hline \multirow{3}{*}{ JM92 Situation } & JP & 8.13 & .000 \\
& JM100 & 2.67 & .027 \\
& JM82 & 7.00 & .000 \\
\hline \multirow{3}{*}{ JM82 Situation } & JP & 1.13 & 1.00 \\
& JM100 & -4.33 & .000 \\
& JM92 & -7.00 & .000 \\
\hline
\end{tabular}

Next, to determine which pair of study situations contributed to significant results for rally length performance, the results in the Within-Subjects Contrasts were referenced. The results of the comparative test in the subjects showed that there was a significant difference in terms of rally length performance between JP-JM100 situation $[\mathrm{F}(1,23)=46.20, \mathrm{p}=.001]$, JM100-JM92 situation $[\mathrm{F}(1,23)=9.88, \mathrm{p}=.005]$ and situation JM92 $\mathrm{JM} 82[\mathrm{~F}(1,23)=31.38, \mathrm{p}=.001]$. These results indicate that all pairs namely JP-JM100 situation, JM100-JM92 situation and JM92-JM82 situation are significant contributors to the test results for rally length performance in this study. Paired comparison results showed significant difference $(p<.05)$ after Type I error was controlled using Bonferroni method for JP-JM100 situation $(\mathrm{p}=.001)$, JP-JM92 situation $(\mathrm{p}=.001)$, JM100-JM92 situation (p. = .027), situation JM100 JM82 $(\mathrm{p}=.001)$ and situation JM92 - JM82 $(\mathrm{p}=.001)$. Meanwhile, the results of the paired comparison showed no significant difference $(p>.05)$ for the JP-M82 situation $(p=1.00)$. The results of Pairwise Comparisons from the aspect of rally length performance for JP, JM100, JM92 and JM82 situations are shown in Table 4.

\section{The Effect of Net Height Scaling on Satisfaction}

One-way ANOVA test for repeated measurements was conducted to see the effect of net height scaling on satisfaction between JP situation, JM100 situation, JM92 situation and JM82 situation. The test results showed that for the pair of participants of this study $(n=24)$, the mean score from the aspect of game satisfaction for situation JM92 (situation JM92: $\mathrm{M}=3.69, \mathrm{SD}=1.10$ ) was higher compared to situation JM82 (situation JM82: $\mathrm{M}=3.33$, $\mathrm{SD}=.996$ ), situation JM100 (situation JM100: $\mathrm{M}=3.21$, $\mathrm{SD}=.988$ ) and situation JP (situation JP: $\mathrm{M}=2.35, \mathrm{SD}=$ 1.39). These results indicate that participants exhibited higher game satisfaction when playing using JM92 situation compared to JP situation, JM100 situation and JM82 situation. The JP situation exhibited the lowest game satisfaction among the study participants are shown in Figure 1 below.

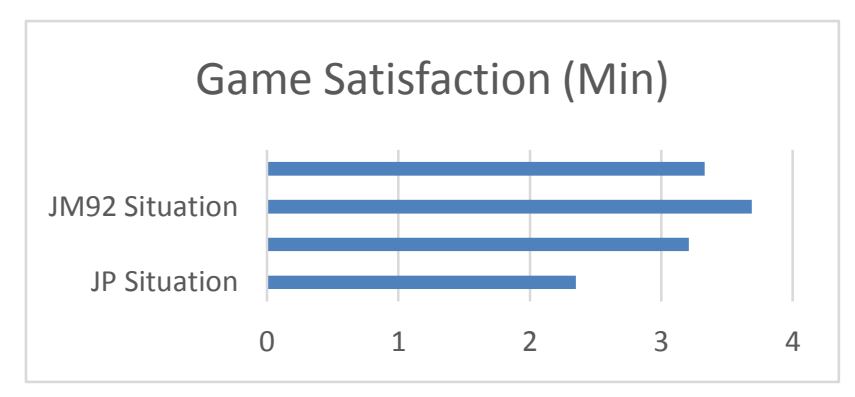

Figure 1. Effect of Net Height Scaling on Satisfaction

$H_{4}$ : There is a difference in the satisfaction of the net

height scaling effect between situations JM82, JM92, JM100 and JP.

The results of Mauchly's Test of Sphericity for the effect of net height scaling on game satisfaction were significant $\mathrm{X}^{2}(5)=53.6, \mathrm{p}=.001$. These results indicate that the adjustment of the degree of freedom for the one -way ANOVA test needs to be done because it does not comply with the conditions of the one-way ANOVA test for repeated measurements. Based on the new degree of freedom after adjustment using Bonferroni method, at the significance level of $\mathrm{p}<.05$, the results of Tests of Within-Subjects Effects showed that there was a significant difference in mean score from the aspect of game satisfaction $[\mathrm{F}(2.69,127)=1.28, \mathrm{p}=.001]$ between situation JP, situation JM100, situation JM92 and situation JM82. Thus, the H4 hypothesis is accepted. These results 
indicate that there are significant differences in aspects of game satisfaction between the four net height situations in this study.

Next, to determine which pairs of situations contributed to significant results, the results in the Tests Table of Within-Subjects Contrasts were referenced. The results of the comparison test in the subjects showed a significant difference from the aspect of game satisfaction for situation JP-JM100 [F $(1,47)=29.8, \mathrm{p}=.001]$, situation JM100-JM92 $[\mathrm{F}(1,47)=42.3, \mathrm{p}=.001]$ and JM92 JM82 $[\mathrm{F}(1,47)=4.47, \mathrm{p}=.040]$. These results indicate that all situational pairs were significant contributors to the test results from the aspect of game satisfaction in this study. These results are also shown by the Pairwise Comparisons table which shows paired comparisons from the aspect of game satisfaction between the four net height situations.

Paired comparison results showed that there was a significant difference $(\mathrm{p}<.05)$ after Type I error was controlled using Bonferroni method for JP-JM100 situation $(\mathrm{p}=.001)$, JP-JM92 situation $(\mathrm{p}=.001)$, JP-JM82 situation $(\mathrm{p}=.001)$, situation JM100 - JM92 (p $=.001)$ and situation JM92 $-\mathrm{JM} 82(\mathrm{p}=.002)$. The results of the study showed that there was no significant difference from the aspect of game satisfaction for the JM82-JM100 situation $(p=1.00)$. The results of the paired comparison from the aspect of game satisfaction are shown in Table 5.

A summary of the results of the one -way ANOVA test for repeated measurements showed that there was a significant difference in mean score $(p<.05)$ for service success performance, shot chance and rally length between JP, JM100, JM92 and JM82 situations. The findings of this study indicate that there is a significant effect of net height scaling on service success performance, shot chance and rally length among children aged seven to nine years in this study. Figure 1 shows the results of comparing the mean scores from the aspect of service success, shot chances, rally length and game satisfaction between the four net height situations in this study.
Table 5. Pairwise Comparisons for Satisfaction

\begin{tabular}{cccc}
\hline $\begin{array}{c}\text { (I) } \\
\text { Game Satisfaction }\end{array}$ & $\begin{array}{c}\text { Game Satisfaction } \\
\text { JP Situation }\end{array}$ & $\begin{array}{c}\text { Mifferences } \\
(\mathrm{I}-\mathrm{J})\end{array}$ & Sig. \\
\hline \multirow{3}{*}{ JM100 } & -.854 & $.000^{*}$ \\
& JM92 & -1.33 & $.000^{*}$ \\
& JM82 & -.979 & $.000^{*}$ \\
\hline \multirow{3}{*}{ JM90 Situation } & JP Situation & .854 & $.000^{*}$ \\
& JM92 & -.479 & $.000^{*}$ \\
& JM82 & -.125 & 1.00 \\
\hline \multirow{2}{*}{ JM82 Situation } & JM82 & 1.33 & $.000^{*}$ \\
& JM100 & .479 & $.000^{*}$ \\
& JM92 & .354 & $.002^{*}$ \\
\hline
\end{tabular}

\section{Service Success, Shot Chances, Rally Length and Game Satisfaction Comparison Between the Four Net Height Situations}

In conclusion, the results of the study indicate that scaling the height of the net is effective in improving the performance of the participants in this study. The findings of the study showed that there were significant differences in terms of service success performance, shot chance and rally length between the four net height situations. This result is further reinforced by the results from the aspect of participant satisfaction which showed a high mean score of the effect of the use of modified net height compared to standard net height. Scaling the height of the net was effective in improving the performance of the game of badminton among children aged seven to nine years in this study are shown in Figure 2 below. 


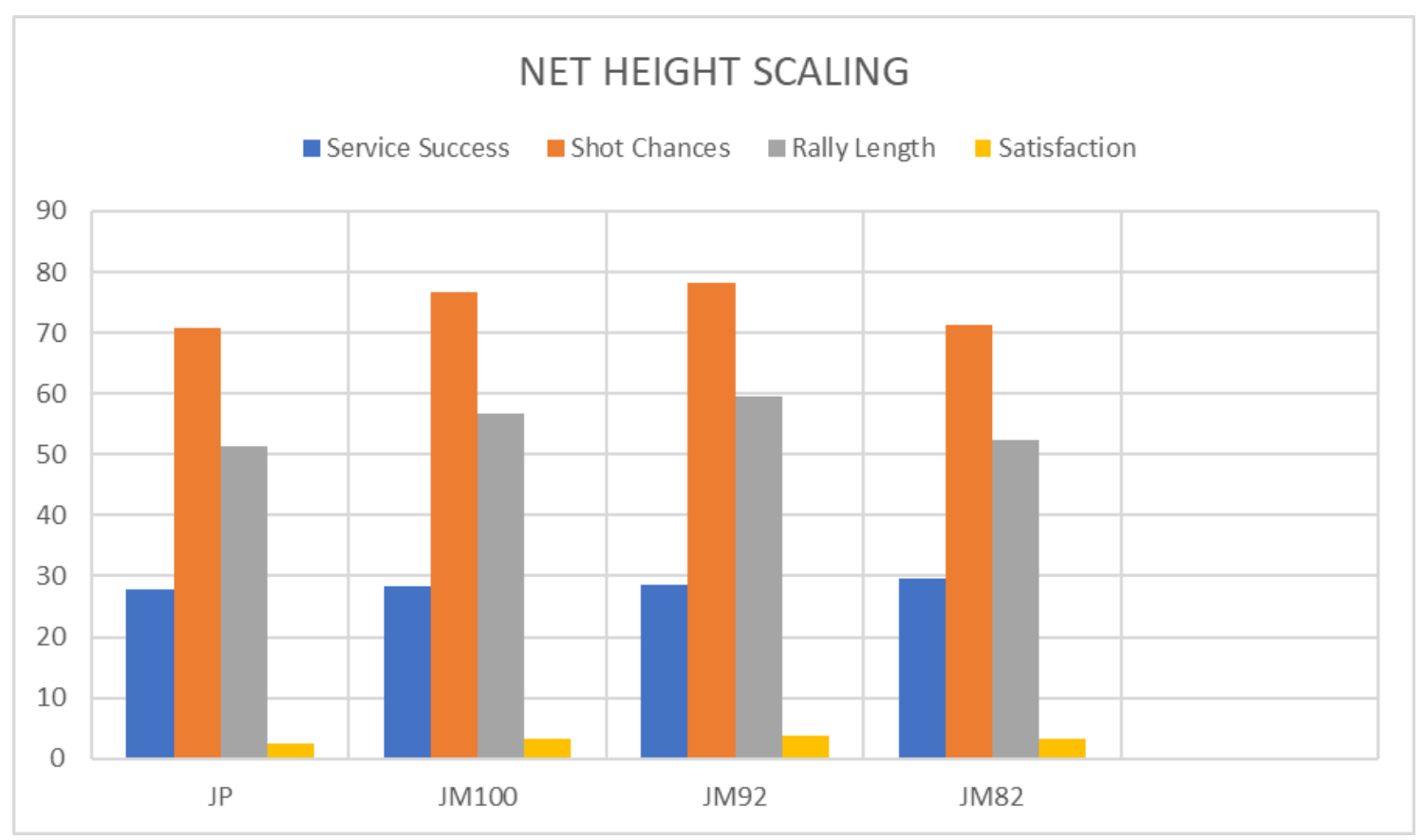

Figure 2. Service Success, Shot Chances, Rally Length and Game Satisfaction Comparison between the Four Net Height Situations

\section{Discussion \& Conclusions}

\section{Service Success}

Inferential statistical analysis showed that there was a significant difference in mean score for service success performance $(\mathrm{p}<.05)$ between JM82 situation, JM92 situation, JM100 situation and JP situation. These results indicate that the net height scaling approach has a significant impact on the performance of service success among children aged seven to nine years. The approach of modifying the height of the net has made it easier for children to perform service shots. The findings of this study are consistent with previous studies in badminton and tennis in that children exhibit improved motor skill performance when a task is simplified through equipment scaling [17]. Descriptive statistical analysis show that the net height scaling approach based on the concept of $82 \%$ (situation JM82) of the average height of participants is more effective in improving the performance of service success in this study.

These results are consistent with Jackson's (2012) study which showed that modified net heights exhibited a significant improvement in service success performance compared to standard net heights. This improvement in service shot performance was associated with a high frequency of mature and sequentially shaped service shot patterns among participants using modification equipment. This suggests that the use of modification equipment allows participants with small body sizes to perform service shots with a more mature pattern.

In turn, this mature serve shot behaviour factor has contributed to a significant improvement in service success performance for modified net heights compared to standard net heights. This means that children aged nine to eleven also benefit from the effect of net height modification. Researchers argue that this scaling approach is capable of having a greater impact among children aged seven to nine who have smaller physical sizes. However, Jackson's study only involved a comparison between two net height situations, namely standard net height and modified net height.

Studies in the game of tennis have also reported a positive impact of the effect of net height scaling on serve success among children [16, 17, 25, 28]. For example, Timmerman [16] who studied the effect of scaling court size and net height on service skill performance while performing paired play among nine-year-old children. However, this study combines two variables namely court size and net height, namely standard court/standard net height, standard court/modified net height, modified court/standard net height, and modified court/modified net height.

Specifically, this study used two net heights namely 0.91 meters (standard net height) and 0.69 meters (modified net height). The study assignment was in the form of a 30 -minute paired match for each study situation. The results of the study showed that the percentage of successful first serve shots was high for the modified court situation/modified net height. Based on the findings of this study, the researcher argues that the net height scaling approach is a strategy that is able to provide an environment for mastery of motor skills that has a high engagement time among children.

Next, Limpens et al. [17] also reported the positive impact of a net height scaling approach on children's 
performance in tennis games. In contrast to Timmerman [16], this study examined the immediate effect of net height reduction on performance characteristics based on $70 \%$ ( 0.91 meters), $60 \%$ ( 0.78 meters), $50 \%$ ( 0.65 meters) and $40 \%$ ( 0.52 meters) of average height children 10 years of age and under. The study assignment involved each pair of participants playing for 25 minutes of a singles event using all four net height situations. The performance of the serve shot in this study was evaluated from the aspects of the first serve that came in, the first serve that hit the net, the direction of the serve and aces.

These results are in line with Harter's Competency Motivation Theory [24]. and Self-Efficacy Theory [23] which relate the role of self-confidence and self-efficacy in motivating individuals to perform a task successfully. According to Harter [24] the level of motivational experience experienced has a relationship with the level of competence felt by a player. Children's self-perception of the ability to perform a task successfully can have a positive or negative impact on the performance and mastery of motor skills.

Thus, through the scaling approach the height of the net has improved children's perceptions and feelings of the level of self-efficacy while performing service shots. This goal can be achieved through the method of reducing the height of the net in accordance with the physical size which has eased the constraints of the task while performing the service shot. Furthermore, this situation has improved the service success performance for the JM82 and JM92 situations in this study.

\section{Opportunity Shot}

Inferential statistical analysis also showed that there was a significant mean score difference $(\mathrm{p}<.05)$ for shot chance performance between the four net height situations in this study. These results indicate that the net height scaling approach is effective in improving shot chance performance among children aged seven to nine years. Descriptive statistical analysis showed that the optimal net height in terms of shot chance performance among children aged seven to nine years was based on $92 \%$ of the average height of the study participants. The findings of this study also revealed that the excessively high net height represented by the JP situation compared to the average height of children was less effective in improving shot chance performance. In addition, the results of the study also showed that net heights that were too low compared to the average height of children were less effective in improving shot chance performance.

The results of this study are consistent with the study of Gimenez-Egido [25,26, 27] who studied the effects of modification of net height and court dimensions on the performance of children under 10 years of age using real competition situations. The height of the modified net in this study was reduced from 0.91 meters to 0.80 meters.
Nevertheless, the results of this study are inconsistent with those of Limpens [17] who studied the immediate effect of net height reduction on tennis game performance characteristics among children aged 10 years and below. The findings of the study showed that by lowering the height of the net to 0.65 meters and 0.52 meters has reduced the chances of a shot obtained by each participant. This is because the effect of reducing the height of the net has encouraged participants to apply the pattern of the game offensively. Timmerman [16] also reported a similar finding that a reduction in net height leads to offensive-shaped play.

This means that the approach of reducing the height of the net does not necessarily have a positive impact on play performance among children. The authors argue that the differences that exist between the findings of the Gimenez-Egido [25] and Limpens [17] is due to the difference factor in terms of net height which is 0.80 meters and 0.65 meters and 0.52 meters. This being the case, the height of the net being too low has reduced the contact time between the rackets or the adaptation of the offensive game pattern. The effect of practicing this game pattern was to reduce the chances of a shot obtained by the study participants.

A net height that is too low will reduce the contact time between the racket and the rally length. Low rally length performance will indirectly reduce shot chance performance. The high frequency of stroke opportunities is critical for the development of motor skills in children.

\section{Rally}

Inferential statistical analysis showed that scaling net height was effective in improving rally length performance among children aged seven to nine years. The researchers argued that this positive result was an effect of the JM92 situation net height corresponding to the children's height allowing them to perform shots in a comfortable position. In turn, this game situation has contributed to the high rally length performance for this situation. These findings are consistent with Limpens [17] who reported that the effect of appropriate and optimal net height scaling was able to improve the mastery of motor skills among young tennis players. The height of the net in line with the physical size of the children allows them to adopt an offensive pattern of play without an increase in the frequency of shot errors. In addition, the low height of the net also encourages children to adapt play patterns that resemble the characteristics of adult play. These play patterns have the potential to develop action-perception skills and decision-making skills in children before being exposed to adult play patterns as adolescence grows.

Researchers argue that by reducing the height of the net to 0.65 meters and 0.52 meters has encouraged players to adopt an offensive game pattern. The approach of reducing the height of the net also encourages the conduct 
of offensive -shaped shots throughout the rally. The practice of this offensive game pattern significantly reduced the length of rallies among the study participants. Researchers also reported that the short rally lengths for both of these situations directly reduced the chances of a shot being obtained. Timmerman [16] have also reported similar findings that by reducing the height of the net leads to offensive -shaped play.

Timmerman [16] reported the negative impact of the effect of scaling net height that is too low on rally length performance in tennis games. Nevertheless, through the reduction of the measurement of the height of the net has had a positive effect on the improvement of the aspect of shot quality which symbolizes high game performance. Offensive -shaped play patterns are associated with fast -paced adult play patterns. Nevertheless, the offensive -shaped pattern of play led to low rally length performance. This statement is consistent with the findings of a study that showed that the lowest net height of 0.52 meters significantly exhibited the lowest rally length [17].

Moreover, the study of Gimenez-Egido [25,26,27] also reported a positive impact of net height scaling on rally length performance using real competition situations. Researchers argue that this low performance is a result of standard net heights that are less appropriate or too high for children aged seven to nine years. These results are contrary to the study of Limpens [17] who reported the standard net height situation (0.91 meters) exhibited the highest rally length performance compared to net heights of 0.52 meters, 0.65 meters and 0.78 meters in tennis games. This high rally length performance is influenced by the time between the racket and the higher racket for the 0.91 meter net height situation. The high time between racket and racket for this situation is an indicator that the child is adopting a defensive play pattern. In general, defensive-shaped play patterns benefit the development of motor skill mastery in children. However, this pattern of play is also able to have implications for the development of perception-action skills, especially anticipation skills.

In conclusion, the findings of the study show. consistent with the concept used to determine the standard net height which is $92 \%$ of the average adult height [15]. Net heights that are too high or too low are also less effective in improving rally length performance in children.

\section{Satisfaction}

The findings of this study demonstrate empirically that providing a favourable motor skills mastery environment that is relevant to the needs of children can bring benefits in terms of perceived competence and increased motivation to participate in sports [29]. In conclusion, the study's findings show that the net height scaling strategy can help children while playing paired games in this study. This is supported by the study's findings, which revealed a high level of game satisfaction for the adjusted net height circumstance, particularly the JM92 situation. Children's efficiency and self-efficacy have improved as a result of a net height scaling strategy that is suited for their physical stature. Scaling the height of the net has provided a high possibility of success, resulting in a conducive and enjoyable motor skills mastery environment that is helpful to children's competence and self-efficacy.

\section{Acknowledgements}

The authors are grateful to Universiti Malaysia Sabah for funding this work through internal university allocation and a research grant.

\section{REFERENCES}

[1] T. B. Tong, "Pendidikan Jasmani dan Kesihatan", Kursus Diploma Perguruan Malaysia, Ipoh: Longman. 2001.

[2] K. E. French, J. Rink, L. Rikard, A. Mays, S. Lynn \& P. Werner, "The Effects of Practice Progressions on Learning Two Volleyball Skills," Journal of Teaching in Physical Education., Vol.10, pp. 261-274, 1991.

[3] T. Buszard, L. Oppici, D. Farrow \& H. Westerbeek, "Implementation of Modified Sport Programme to Increase Participation: Key Stakeholder Perspectives". Journal of Sport Sciences, vol. 38, no. 8, pp. 1-8, 2020. https://doi:10.1080/02640414.2020.1737370.

[4] T. Purcell, "A Collaborative Approach to Developing an Interdisciplinary Unit”. Research Quarterly for Exercise and Sport, vol. 76, pp. 60-61. 2005.

[5] B. Kelley \& C. Carchia, "Hey, Data......Swing!". ESPN, 2013.http://www.espn.com/espn/story/_id/9469252/hidde n-demographics-youth sports espn-magazine.

[6] J. Crane \& V. Temple, "A Systematic Review of Dropout from Organized Sport among Children and Youth". European Physical Education Review, vol. 21, no.1, pp. 114-131. 2015.

[7] K. M. "Newell, Constraints on the Development of Coordination". In M. Wade \& H. T. A. Whiting (eds.). Motor Development in Children: Aspects of Coordination and Control. Dordrecht, The Netherlands: Martinus Nijhoff. pp.341-360. 1986.

[8] I. Renshaw, J. Y. Chow, K. Davids \& J. Hammond, "A Constraint-Led Perspective to Understanding Skill Acquisition and Game Play: A Basis for Integration of Motor Learning Theory and Physical Education Praxis?" Physical Education and Sport Pedagogy, vol. 15, no. 2, pp. 117-137, 2010

[9] J. Y. Chow, "Nonlinear Learning Underpinning Pedagogy: Evidence, Challenges, and Implications". Quest, vol. 65, pp. 469-484, 2013.

[10] V. Correia, J. Carvalho, D. Araujo, E. Pereira, \& Davids, "Principles of Nonlinear Pedagogy in K. Sport Practice", 
Physical Education Sport Pedagogy, vol. 24, pp. 117-132, 2019.

[11] D. Farrow \& M. Reid. "The Effect of Equipment Scaling on the Skill Acquisition of Beginning Tennis Players". Journal of Sports Sciences, vol. 28, pp. 723-732, 2010.

[12] T. Buszard, M. Reid, R. S. W. Masters, \& D. Farrow, "Scaling the Equipment and Play Area in Children's Sport to Improve Motor Skill Acquisition: A Systematic Review." Sports Medicine, vol. 46, pp. 829-843, 2016.

[13] S. L. Jackson, "Badminton Serves Using Body Scaled Equipment." Arkansas Journal, vol. 47, no. 1, pp. 2-11. 2012.

[14] E. Timmerman, J. D. Water, K. Kachel, M. Reid, D. Farrow \& G. Savelsbergh, "The Effect of Equipment Scaling on Children's Sport Performance: The Case for Tennis." Journal of Sport Sciences, vol. 33, no. 10, pp. 1093-1100. 2015.

[15] V. Limpens, T. Buszard, E. Shoemaker, G. J. P. Savelsberg \& M. Reid, "Scaling Constraints in Junior Tennis: The Influence of Net Height on Skilled Player's Match-Play Performance". Research Quarterly for Exercise and Sport, vol. 89, no. 1, pp. 1-10. 2018.

[16] S. M., Vial, J. Cochrane, A. J Blazevich, \& J. L. Croft, "Using the trajectory of the shuttlecock as a measure of performance accuracy in the badminton short serve", International Journal of Sports Science \& Coaching, vol. 14, no. 1, pp. 91-96. 2019.

[17] I. Hussain, S. Ahmed, A.Mohammad, A. Khan \& M. A. Bari. "Videographical Analysis of Short Service in Badminton". Journal of Education and Practice, vol. 2, no. 2, 2010 .

[18] Saleem Ahmed, Sartai Khan \& Manu Mishra Ouheed Akhter. "Service Badminton: A Biomechanical Study". Indian Streams Research Journal, vol. 5, no. 2, 2015.

[19] A. M. Nor Azmi, P. K. Suppiah, L. F. L, Jeffery, H. Noordin $\&$ M. S. Samsir. "The influence of modified equipment in developing skills in badminton". Malaysian Journal of Movement, Health \& Exercise, vol. 9, no.1, pp. 67-76. 2020.

[20] Y.P. Chua, "Kaedah dan statistik penyelidikan: kaedah penyelidikan”. Mcgraw-Hill Education, Shah Alam. 2011.

[21] S. Harter, "Effectance Motivation Reconsidered: Toward a Developmental Model”. Human Development, vol. 21, pp. 34-64. 1978.

[22] J. M. Gimenez-Egido, E. Ortega-Toro, J. M. Palao, I. Verdu-Conesa, \& G. Torres-Luque, "Effect of Modification Rules in Competition on Technical-Tactical Action in Young Tennis Players (Under-10)". Frontier in Psychology, vol. 10. 2020.

[23] K. P. Henry, M. N. Nazarudin \& P. K. Suppiah, "Kesan Penskalaan Tinggi Jaring terhadap Prestasi Peluang Pukulan Permainan Badminton dalam Kalangan Kanak-Kanak". International Journal of Education, Psychology and Counseling, vol. 5, no.34, pp. 234-244. 2020

[24] K. P. Henry, M. N. Nazarudin \& P. K. Suppiah, "Kesan Penskalaan Tinggi Jaring Terhadap Prestasi Panjang Rali Permainan Badminton Dalam Kalangan Kanak-Kanak". International Journal of Education, Psychology and Counseling, vol. 5, no. 34, pp. 245-255.

[25] Septian Williyanto, Agus Wiyanto, Nurhadi Santoso, Masri, "Backhand Serve Test Model for Junior Badminton Athletes," International Journal of Human Movement and Sports Sciences, Vol. 9, No. 4A, pp. 112 - 118, 2021. DOI: 10.13189/saj.2021.091319.

[26] Mohamad Nizam Nazarudin , Mohd Firdaus Abdullah , Mohd Radzani Abdul Razak, Abu Yazid Abu Bakar, Denise Koh Choon Lian, Wan Ahmad Munsif Wan Pa, "Dealing with Delayed Onset Muscle Soreness (DOMS): Foam Roller or Mechanical Manipulation of Body Tissue," International Journal of Human Movement and Sports Sciences, Vol. 9, No. 3, pp. 383 - 393, 2021. DOI: 10.13189/saj.2021.090301. 